\title{
O ATUAL RESGATE CRÍTICO DA TEORIA MARXISTA DA DEPENDÊNCIA
}

\author{
THE CURRENT CRITICAL RETRIEVAL OF THE MARXIST THEORY OF DEPENDENCE
}

\author{
Marcelo Dias Carcanholo ${ }^{1}$
}

Resumo O objetivo central deste artigo é discutir as principais categorias da teoria marxista da dependência. Tal esforço se justifica por causa do resgate que essa perspectiva teórica vem recebendo nos últimos anos. Em primeiro lugar, discute-se o significado original do que a teoria entende por dependência e, a partir disso, a natureza específica da inserção das economias dependentes no capitalismo mundial. Em seguida, além de se reafirmar o caráter central da superexploração da força de trabalho como característica específica dessas economias, argumenta-se que esse caráter só é inteligível quando entendido como a resposta do capitalismo dependente às diferentes formas de transferência de valor para as economias centrais. Em virtude do anterior, o trabalho conclui com apontamentos sobre as direções que podem ser seguidas por um resgate crítico da teoria marxista da dependência.

Palavras-chave dependência; superexploração; marxismo.
Abstract The central purpose of this article is to discuss the main categories of the Marxist Theory of Dependence. This effort is justified because this theoretical perspective has been being retrieved in recent years. Firstly, there is a discussion on the original meaning of what the theory understands by dependence and, based on that, the specific nature of the integration of economies dependent on world capitalism. Then, in addition to reaffirming the central character of the overexploitation of labor as a specific feature of these economies, it is argued that this is only intelligible when understood as the response of dependent capitalism to different forms of transfer of value to the central economies. In view of the foregoing, the article concludes with notes on the directions that can be taken by a critical recovery of the Marxist theory of dependence.

Keywords dependence; overexploitation; Marxism. 
Teoria marxista da dependência 2 é o termo pelo qual ficou conhecida a versão que interpreta, com base na teoria de Marx sobre o modo de produção capitalista, na teoria clássica do imperialismo e em algumas outras obras pioneiras sobre a relação centro-periferia na economia mundial, a condição dependente das sociedades periféricas como um desdobramento próprio da lógica de funcionamento da economia capitalista mundial. Essa teoria foi constituída e teve o seu auge nos anos 1960. A partir daí, por várias razões, ${ }^{3}$ foi completamente esquecida não só pela teoria social hegemônica, como também por boa parte da tradição mais crítica do pensamento social.

Não é uma casualidade histórica que essa teoria venha sendo reabilitada a partir da segunda metade dos anos 1990 e, de forma mais intensa, neste século XXI,4 justamente o momento em que o aguçamento da condição dependente das economias periféricas, como resultado da implantação intensa e massiva da estratégia neoliberal de desenvolvimento, tem se verificado.

O resgate crítico dessa tradição é fundamental para o entendimento da inserção subordinada que as economias dependentes, e em específico as latino-americanas, apresentam na atual fase do capitalismo contemporâneo. Resgate crítico aqui significa uma reavaliação das principais teses da teoria marxista da dependência que não cometa dois tipos de equívocos muito comuns no pensamento social: utilização acrítica das categorias, conclusões e níveis de abstração que essa tradição utilizou para interpretar uma época histórica do capitalismo, desrespeitando, com isso, as especificidades do capitalismo e da dependência contemporâneas; e exasperação - e, portanto, mistificação - dessas especificidades, levando, no limite, à conclusão de que a referida teoria teria de ser inteiramente reformulada.

Esse resgate crítico implica, portanto, o resgate das principais teses da teoria marxista da dependência - centro e periferia como elementos contraditórios de uma mesma unidade dialética, o capitalismo mundial; identificação dos condicionantes estruturais da dependência e necessidade de sua articulação dialética com as distintas especificidades conjunturais; papel central da superexploração da força de trabalho, entre outras -, ao mesmo tempo em que elas se articulam com as especificidades históricas do capitalismo contemporâneo.

O que este trabalho pretende é apresentar sinteticamente as principais teses dessa teoria, uma vez que se considera como uma das características de seu atual resgate o profundo desconhecimento de seu núcleo central, seja para detratá-la, seja para recuperá-la.

\section{Teoria marxista da dependência: significado da categoria dependência}

Em primeiro lugar, é preciso afastar toda e qualquer noção mais tradicional do termo desenvolvimento, se o que se pretende é resgatar/construir uma 
interpretação com base em Marx para as diferentes formas de inserção das economias dentro da lógica mundial de acumulação de capital. A noção corriqueira de desenvolvimento é fruto de uma tradição positivista, com alguma influência moralista, que enxerga no curso da história a possibilidade de uma trajetória quase linear de uma situação 'pior' para outra 'melhor' - um verdadeiro progresso -, atribuindo a essa trajetória possível o termo desenvolvimento.

Para uma concepção baseada em Marx nada pode ser mais estranho. $\mathrm{O}$ termo desenvolvimento para ele tem um sentido de processualidade, isto é, como determinada estrutura social se desenrola com o passar do tempo, como as leis de funcionamento de determinada sociabilidade se manifestam em uma trajetória de tempo - manifestações essas que sempre possuem uma determinação histórica. Não existe, portanto, nenhuma concepção de trajetória do 'pior' para o 'melhor', uma vez que o desenvolvimento das leis implica a complexificação de todas as contradições próprias dessa formação histórica específica. Assim, no caso do desenvolvimento histórico, tem-se a processualidade da história por distintos modos de produção, sempre dialética e historicamente determinados, e, talvez o mais importante, sem nenhuma teleologia e/ou determinismo histórico dado a priori.

No caso do desenvolvimento histórico dentro do modo de produção capitalista - o que nos permite entender uma historicidade do e no capitalismo -, a noção de desenvolvimento significa o desenrolar contraditório, dialético, das leis de tendência do modo de produção capitalista. 5 A noção de dependência defendida pela teoria marxista toma isso como base e entende o processo de acumulação em escala mundial como uma unidade dialética entre o desenvolvimento e o subdesenvolvimento. Ou melhor, entende que esse processo pressupõe desenvolverem-se determinadas economias - no sentido do desenrolar das leis gerais do modo de produção capitalista - em ritmo mais acelerado do que outras. A consequência disso é que se supera a constatação óbvia de que as distintas economias assumem uma relação de interdependência, de forma que a divisão internacional do trabalho configura uma situação de dependência,

(...) entendida como uma relação de subordinação entre nações formalmente independentes, em cujo marco as relações de produção das nações subordinadas são modificadas ou recriadas para assegurar a reprodução ampliada da dependência (Marini, 2005a, p. 141).

A dependência, assim, seria uma situação em que uma economia estaria condicionada pelo desenvolvimento e expansão de outra à qual está subordinada, o que se expressaria no fato de a economia dominante poder expandir-se autossustentadamente - de forma contraditória e dialética, como característico do capitalismo - enquanto a dependente só o faria como reflexo 
dessa expansão, ou de forma constrangida pela situação de dependência, tendo efeitos positivos e negativos sobre o seu desenvolvimento.

Dessa noção deriva um entendimento de que aquilo que se costuma entender corriqueiramente como subdesenvolvimento não é senão uma parte necessária do processo de expansão do capitalismo mundial, não podendo, portanto, ser 'superada' dentro dos seus marcos.

É preciso, no entanto, fazer uma ressalva. Da forma como a teoria marxista da dependência apresenta essa categoria, pode entender-se - o que não é incomum - a relação de dependência como a 'exploração' de determinado país por outro. Essa visão moralista, tipicamente weberiana, deveria ser completamente estranha à teoria marxista da dependência, ainda que algumas passagens não deixem isso claro. Como já notou Marx: "é, em primeiro lugar, uma falsa abstração considerar uma nação, cujo modo de produção repousa no valor e que, além disso, está organizado capitalistamente, como sendo um corpo coletivo que trabalha apenas para as necessidades nacionais" (1983, v. 5, p. 293). Isso significa que a categoria central de análise é o capital, e não a 'nação', de forma que a situação de dependência é fruto de um desenvolvimento desigual e combinado das leis de funcionamento do capital, em distintas partes do mundo.

\section{Troca desigual e transferência de valor}

Porém, como se dá essa relação de dependência, isto é, quais são os condicionantes estruturais que definem uma economia dependente? De forma sintética, a situação dependente se caracteriza pelo fato de que uma parte do (mais) valor produzida nessa economia não é apropriada nela, mas nas economias centrais, e passa a integrar, portanto, a dinâmica de acumulação de capital das últimas, e não das primeiras. O processo de transferência de (mais) valor ficou conhecido na discussão dos anos 1960 como troca desigual.

Marini (2005a), quando explica o segredo da troca desigual no plano do comércio mundial, faz referência a dois mecanismos. Do nosso ponto de vista, porém, ele estaria tratando, na verdade, de três. Ainda que relacionados, esses mecanismos dizem respeito a diferentes níveis de abstração no processo das trocas mercantis. Em um primeiro nível, e considerando que distintos capitais podem produzir uma mesma mercadoria com diferentes graus de produtividade, isso implica que cada um dos capitais possuiria valores individuais distintos, tanto menores quanto maior for a produtividade do capital em questão. Como a mercadoria é vendida pelo valor de mercado, ou social, segundo o tempo de trabalho socialmente necessário, os capitais com produtividade acima da média venderiam suas mercadorias pelo valor de mercado, 6 apropriando-se, portanto, de uma mais-valia para 
além daquela que eles mesmos produziram: a mais-valia extraordinária. Assim, nesse nível de abstração mais elevado, a lei do valor no plano da economia mundial implicaria que economias que possuem capitais com produtividade abaixo da média mundial tenderiam a produzir mais valor do que aquele de que realmente conseguem se apropriar. Esse desnível na produtividade de mercadorias produzidas tanto em uma (economia central) quanto em outra (economia dependente) permite um primeiro mecanismo de transferência de mais-valia produzida na última e que é apropriada/acumulada na primeira.

Um segundo mecanismo de transferência se apresenta quando consideramos um nível de abstração menor nas trocas mercantis. Nos termos de Marx, quando saímos do plano da concorrência dentro de um mesmo setor, e consideramos a concorrência entre distintas esferas de produção, naquilo que esse autor trabalhou como a formação dos preços de produção e da taxa média de lucro (Marx, 1983, vol. 5, cap. 9), temos o aparecimento de um lucro extraordinário para aqueles setores que produzem com maior produtividade em relação à média da economia. Ali é demonstrado que setores que produzem suas mercadorias específicas com composição orgânica do capital (produtividade) acima da média apresentarão um preço de produção de mercado acima dos valores de mercado e, portanto, venderão ${ }^{7}$ suas mercadorias por um preço que lhes permitirá apropriar-se de mais valor do que produziram. O contrário acontece naqueles setores que produzem suas mercadorias com produtividade abaixo da média da economia como um todo. Aqui temos o segundo mecanismo de transferência de valor. Como os capitais das economias dependentes tendem, em geral, a apresentar produtividade abaixo da média de todos os setores da economia mundial, ocorre a transferência de uma parte da mais-valia produzida nas economias dependentes, que será apropriada, na forma de um lucro médio superior à mais-valia produzida, pelos capitais operantes nas economias centrais. ${ }^{8}$ Marini (2005a) relaciona esse mecanismo ao monopólio de produção de mercadorias com maior composição orgânica do capital pelos capitais operantes nas economias centrais.

No entanto, o monopólio se relaciona também com o último nível de abstração das trocas mercantis, os preços efetivos de mercado, o que nos dá um terceiro mecanismo de transferência de valor. Quando determinados capitais têm um grau de monopólio razoável em seus mercados específicos, isso permite a eles manter, por determinado tempo, preços de mercado por sobre os preços de produção de mercado, isto é, permite sustentar temporariamente volumes de produção abaixo das demandas. Como os preços de mercado estariam, nessa situação, acima dos preços de produção, para além das oscilações conjunturais, esses capitais poderiam apropriar-se de um lucro efetivo acima do médio, uma massa de valor apropriado além daquele que, de fato, foi produzido por esses capitais. 
Esses três mecanismos apenas no plano do comércio mundial - da troca desigual, nos termos de Marini - ajudam-nos a entender um condicionante estrutural da dependência, pois já é possível compreender a forma heterogênea de inserção na economia mundial apenas no plano da circulação de mercadorias. Economias centrais, que tendem a possuir capitais com maior composição orgânica do capital em relação à média (do seu setor e entre outros setores de produção), também tendem a se apropriar de um valor produzido por capitais operantes nas economias dependentes.

Essa condição estrutural obriga os capitalismos dependentes a compensar de alguma forma essa parcela da mais-valia que é transferida, para que possam se desenvolver (de forma capitalista) ou, como deixa claro Marini, diante desses "mecanismos de transferência de valor, baseados seja na produtividade, seja no monopólio da produção, podemos identificar - sempre no nível das relações internacionais de mercado - um mecanismo de compensação" (2005a, p. 152). Assim, mesmo com uma transferência de valor produzido na economia dependente, é possível um desenvolvimento (capitalista!) nessas economias. Mas como?

\section{Centralidade da categoria superexploração da força de trabalho}

Dada a importância que a superexploração tem na teoria marxista da dependência, é fundamental e obrigatório precisar exatamente seus significado e status teórico dentro da teoria marxista que procura dar conta das especificidades das sociedades dependentes.

A primeira precisão que necessita ser feita é se a superexploração diz respeito ao trabalho, ou à força de trabalho. Marini (2005a e 2005b) usa o termo superexploração do trabalho, mas não é tão incomum encontrar nos trabalhos que tratam da teoria marxista da dependência o termo superexploração da força de trabalho. Não se trata de mero preciosismo terminológico. Além disso, deve fazer algum sentido, para estudar o significado da superexploração, saber o que significa exploração e, ademais, exploração do quê.

Se o referencial teórico principal é a concepção de Marx sobre o modo de produção capitalista, recorramos a esse autor para ver como ele trata o tema. Marx define a taxa de mais-valia da seguinte forma:

(...) a mais-valia está para o capital variável como o mais-trabalho para o necessário, ou a taxa de mais-valia $\mathrm{m} / \mathrm{v}$ = mais-trabalho/trabalho necessário. Ambas as proporções expressam a mesma relação de forma diferente (...). A taxa de mais-valia é, por isso, a expressão exata do grau de exploração da força de trabalho pelo capital ou do trabalhador pelo capitalista (1983, vol. 1, p. 177). 
Em primeiro lugar, deve-se assinalar, desde já, que Marx usa o termo exploração da força de trabalho, ainda que em alguns poucos momentos de $O$ capital ele possa utilizar o termo exploração do trabalho. Em segundo lugar, percebe-se claramente que o autor entende a taxa de mais-valia, isto é, a proporção entre a mais-valia $(\mathrm{m})$ produzida e o elemento do capital produtivo realmente responsável pela produção de valor, a força de trabalho, que, em termos de valor, é o capital variável (v), como a “expressão exata" do grau de exploração da força de trabalho. Embora Marx não use o termo superexploração da força de trabalho, daqui, poder-se-ia interpretar - como de fato fazem alguns - que a superexploração em Marx corresponderia, ${ }^{9}$ simplesmente, a uma maior exploração, ou seja, a uma elevação da taxa de mais-valia. Entretanto, não é com esse sentido que a categoria foi utilizada por Marini (2005a e 2005b), 10 por exemplo, ainda que alguns autores da tradição da teoria marxista da dependência não tratem claramente da diferença que existe entre a categoria e as distintas formas de obter a elevação da taxa de mais-valia, como veremos adiante.

Antes disso, deve-se esclarecer o significado em Marx do termo 'exploração'. Ela não pode ser entendida com base em uma concepção moralista, maniqueísta, como se a exploração pelo capital significasse um uso indevido, injustificado, um verdadeiro ato de crueldade do capital contra o elemento subjetivo do processo de produção, a força de trabalho (o trabalhador), 11 com o único intuito de se apropriar de uma parcela do resultado do trabalho desse, na forma da mais-valia. Essa interpretação moralista tende a identificar na mais-valia o resultado de um roubo por parte do capital. Ainda que realmente o intuito do capital seja a apropriação da mais-valia com base no trabalho que a força de trabalho realiza no processo produtivo, para além daquele trabalho que é necessário para recompor suas condições de existência, não há nada mais distante de Marx do que interpretar isso com esse viés moralista.

O termo exploração em Marx tem um sentido mais amplo. Significa usar, utilizar, consumir ou explorar a capacidade que a mercadoria em questão possui de satisfazer a necessidade de quem a utiliza. Para sermos mais rigorosos, e já utilizando a teoria do valor de Marx, exploração significa consumir/realizar o valor de uso (a capacidade que uma mercadoria possui de, mediante as suas propriedades materiais/objetivas, satisfazer as necessidades humanas - nesse caso, as necessidades de valorização do capital) próprio da mercadoria em questão. Como os critérios de justiça e moralidade são também construídos historicamente e, na sociedade capitalista, eles estão subsumidos à lógica do valor mercantil, considera-se justo que: a) as mercadorias sejam compradas e vendidas pelos seus valores, isto é, que a troca de equivalentes seja a norma das relações mercantis; e b) quem compra uma mercadoria adquire o direito de utilizar como bem 
entender essa mercadoria, ou seja, de se apropriar do resultado do consumo do valor de uso da mercadoria. Marx é o único autor que consegue explicar a mais-valia (lucro) mesmo assumindo a troca de equivalentes como norma das relações mercantis. Isso significa que o capital, mesmo pagando um salário equivalente ao valor da força de trabalho, consegue apropriar-se de um valor excedente, a mais-valia. Essa última se explica, portanto, pela dialética da mercadoria força de trabalho.

Como toda e qualquer mercadoria, a força de trabalho é uma unidade dialética entre seu valor de uso e seu valor. Esse último equivale ao tempo de trabalho socialmente necessário para produzir e reproduzir a capacidade de trabalho, de acordo com determinações sociais e históricas. Assumir a troca de equivalentes significa assumir que os salários pagos correspondem a esse valor da força de trabalho. O valor de uso dela, por outro lado, é dado pela sua serventia, por aquilo que a força de trabalho é capaz de fazer, o exercício efetivo de sua capacidade de trabalho. Assim, o resultado da realização da capacidade de trabalho é o trabalho propriamente dito, junto com os meios de produção, o processo produtivo. Como o trabalho é a substância/fundamento do valor, o resultado do consumo do valor de uso da força de trabalho implica criação de valor. E como esse resultado é de propriedade de quem comprou a capacidade de trabalho, o valor novo gerado no processo produtivo é, e deve ser, apropriado pelo capital. Evidentemente que o capital procurará determinar uma jornada de trabalho (responsável pela criação desse valor novo) além daquele tempo de trabalho que produzirá um valor equivalente ao valor da força de trabalho. Essa diferença é justamente a mais-valia, o trabalho excedente.

No texto em que procura responder às primeiras críticas que Dialética da dependência sofreu, Marini (2005b) deixa clara a centralidade, e a especificidade, da categoria superexploração para a teoria marxista da dependência quando afirma que as questões substantivas do Dialética da dependência "estão reafirmando a tese que se afirma ali, isto é, a de que o fundamento da dependência é a superexploração do trabalho" (Marini, 2005b, p. 165). Fica evidente nesse trecho que a superexploração é uma categoria específica do capitalismo dependente. 12 E qual seria a razão disso? Qual é a especificidade que define a condição dependente? Como visto, como resultado da inserção subordinada das economias dependentes na lógica mundial da acumulação capitalista se definem mecanismos estruturais de transferência de valor produzido nessas economias, mas que, na verdade, é realizado e acumulado no ciclo do capital das economias centrais. E, em função dessa transferência estrutural de valor, o desenvolvimento do capitalismo dependente requer algum tipo de mecanismo de compensação.

Que mecanismo de compensação é esse? Justamente a superexploração da força de trabalho! Isto comprova que: a) se trata de uma categoria que 
não pode ser confundida com as distintas formas que existem no capitalismo para elevar a taxa de mais-valia (taxa de exploração), ainda que esta categoria só se possa materializar através justamente destas formas; e b) a superexploração da força de trabalho é uma categoria específica da economia dependente - portanto em um menor nível de abstração do que as leis gerais do modo de produção capitalista - ainda que, evidentemente, as distintas formas de elevar a taxa de exploração (mais-valia) sejam características de toda e qualquer economia capitalista. Como o próprio Marini afirma:

O que aparece claramente, portanto, é que as nações desfavorecidas pela troca desigual não buscam tanto corrigir o desequilíbrio entre os preços e o valor de suas mercadorias exportadas (o que implicaria um esforço redobrado para aumentar a capacidade produtiva do trabalho), mas procuram compensar a perda de renda gerada pelo comércio internacional por meio do recurso de uma maior exploração do trabalhador (Marini, 2005a, p. 153).

Assim, esse 'mecanismo de compensação' seria a única forma de o capitalismo dependente se desenvolver (capitalistamente), o que comprova a especificidade (objetiva e, portanto, categorial) do capitalismo dependente. ${ }^{13}$

No item 3 de Dialética da dependência, "A superexploração do trabalho", Marini começa enumerando as formas/mecanismos de elevação da exploração do trabalho, 14 e isso pode ter contribuído para a confusão corriqueira que se faz entre a categoria - maior contribuição teórica desse autor - e as formas específicas de se obter a elevação do grau de exploração. Tanto é assim que o próprio autor, em um dos vários momentos em que procura esclarecer seu significado, define a superexploração como formas/mecanismos de elevar a exploração do trabalho:

(...) em termos capitalistas, esses mecanismos (que ademais podem se apresentar, e normalmente se apresentam, de forma combinada) significam que o trabalho é remunerado abaixo de seu valor e correspondem, portanto, a uma superexploração do trabalho (Marini, 2005a, p. 157).

Aqui, formas de elevar a exploração e superexploração são tratadas teoricamente em uma relação de correspondência, conforme o termo utilizado pelo autor. Não dá para dizer que correspondência signifique definição, mas, no mínimo, um melhor esclarecimento por parte do autor seria necessário, o que não é feito. Em outro texto, quando ele se vê obrigado a responder às críticas que lhe foram formuladas em seu trabalho original, ele afirma que:

(...) a superexploração é melhor definida pela maior exploração da força física do trabalhador, em contraposição à exploração resultante do aumento da produtividade, 
e tende normalmente a se expressar no fato de que a força de trabalho se remunera abaixo do seu valor real (Marini, 2005b, p. 189).

Aqui ele é muito mais claro, inclusive ao utilizar o termo definição, e não correspondência. A superexploração se definiria por uma elevação da taxa de exploração que não passa por elevação da produtividade. E por que não poderia passar? Justamente porque isso está vedado às economias dependentes. Trata-se, portanto, de uma característica específica dessas últimas. Superexploração, assim, é uma categoria específica delas, ao mesmo tempo em que se manifesta em formas/mecanismos específicos de obter a elevação da taxa de exploração.

Em termos mais rigorosos, ainda que seja utilizado o mesmo termo para duas coisas diferentes, a proposta teórica de Marini para entender a especificidade das economias dependentes faz muito mais sentido quando se compreende que o mecanismo de compensação para elevar a taxa de acumulação do capitalismo dependente é uma necessidade dele em virtude dos condicionantes estruturais de dependência (distintas maneiras de transferência do valor produzido nessas economias e que vai fazer parte do ciclo de acumulação das economias centrais), e que as distintas formas de obter esse mecanismo de compensação não podem ser confundidas com o mecanismo em si.

\section{O capitalismo dependente e a atualidade da teoria marxista da dependência}

A superexploração da força de trabalho, que redunda em um pagamento de salário para a força de trabalho abaixo do seu valor, produz, na economia dependente, uma distribuição regressiva tanto da renda quanto da riqueza, bem como a intensificação das mazelas sociais, aprofundando uma característica já própria de qualquer economia capitalista. Dessa forma, podem ser elencados os seguintes componentes da dependência: a) superexploração da força de trabalho; b) transferência de valor para as economias centrais no plano do comércio internacional (troca desigual); c) remessa de (mais) valor para as economias centrais, sob outras formas (pagamento de juros e amortizações de dívidas, transferências de lucros e dividendos, pagamento de royalties etc.); d) alta concentração de renda e riqueza; e e) agravamento dos problemas sociais. Mais do que o conjunto desses cinco elementos, o que define a condição dependente é a sua articulação concreta, no que pode ser definido como a forma, de fato, como se desenvolve o capitalismo dependente.

Se o que discutimos anteriormente faz algum sentido, os elementos b) e c) - isto é, as distintas formas em que a economia dependente transfere parte do seu (mais) valor produzido para as economias centrais - definiriam 
os condicionantes estruturais da dependência. A situação concreta das economias dependentes é dada, em momentos históricos específicos, por esses condicionantes estruturais, aliados aos determinantes conjunturais da situação externa: crescimento da economia mundial, que dá as possibilidades de mercados externos para os produtos exportados pelas economias dependentes, definindo as condições de realização do valor produzido pela economia dependente no mercado mundial; e a situação específica do mercado de crédito internacional, que define o volume de capitais externos disponível no cenário internacional passível de ser atraído para as economias dependentes a fim de financiar os problemas estruturais de contas externas, assim como o preço (taxa de juros) necessário para essa atração.

Quando o cenário externo é favorável, com a economia mundial crescendo e uma facilidade de obtenção do crédito internacional, existe tendencialmente maior margem de manobra para as economias dependentes contornarem os condicionantes estruturais de sua dependência. Quando os elementos conjunturais se agravam - em um cenário de crise mundial aguda, como se vive neste momento, por exemplo - a condição estrutural dependente é agravada.

Independentemente das oscilações cíclicas da conjuntura externa, os condicionantes estruturais da dependência obrigam o capitalismo dependente a superexplorar a força de trabalho como única alternativa para um desenvolvimento capitalista interno. Essa resposta do capitalismo dependente à crescente transferência de seu (mais) valor produzido gera, como consequência, a distribuição regressiva de renda e riqueza, assim como o agravamento dos problemas sociais. É essa a articulação dos componentes da dependência que definem a possibilidade do desenvolvimento capitalista nessas regiões.

Justamente em razão disso, é possível pensar uma historicidade da dependência, com base nos distintos momentos históricos pelos quais passou, e ainda passará, o capitalismo mundial. Uma das linhas de pesquisa mais profícua para a teoria marxista da dependência neste momento é a análise dos determinantes da crise atual do capitalismo contemporâneo, a maneira pela qual o imperialismo se manifesta de forma específica nesta fase histórica e, consequentemente, o caráter histórico específico da dependência na atualidade. 15

Além da interpretação do momento histórico atual, o resgate feito hoje em dia da teoria marxista da dependência passa também, para o entendimento de situações concretas, pela recuperação de algumas de suas categorias. O maior exemplo disso talvez seja o da categoria subimperialismo. Para Marini,

(...) é possível afirmar que o subimperialismo corresponde, por um lado, ao surgimento de pontos intermediários na composição orgânica do capital em escala 
mundial - na medida em que aumenta a integração dos sistemas de produção - e, por outro, à chegada de uma economia dependente à fase do monopólio e do capital financeiro. Neste sentido, em nossos dias, o Brasil se identifica como a mais pura expressão do subimperialismo (2012, p. 41).

Ainda nos anos 1960-1970, Ruy Mauro Marini procurou interpretar a entrada do capital externo produtivo em algumas economias dependentes como resultado da transferência para a periferia de algumas etapas inferiores do processo produtivo, o que acarretou uma elevação da composição orgânica do capital nas economias que receberam esse capital. Isso fez essas economias elevarem as suas composições orgânicas do capital em relação à média da economia mundial e, no plano do comércio internacional com alguns parceiros regionais, replicar os mecanismos de transferência de (mais) valor que o imperialismo sustenta com as economias dependentes para seus parceiros regionais. A esse processo, Marini denominou subimperialismo. Não é casualidade histórica que o papel assumido pela economia brasileira hoje na integração regional pela qual passa a América Latina, do ponto de vista de quem procura resgatar a teoria marxista da dependência, seja visto sob a ótica dessa categoria resgatada.

De uma forma ou de outra, o necessário resgate crítico da teoria marxista da dependência que se efetua hoje deve não apenas divulgar as ideias de seus principais autores, amplamente desconhecidas, mas, ao mesmo tempo, confrontá-las com a especificidade do atual momento histórico vivido pelas economias dependentes. Essa é a melhor maneira de prestar homenagem a esses pioneiros.

\section{Notas}

1 Professor associado da Faculdade de Economia da Universidade Federal Fluminense (UFF), Niterói, Rio de Janeiro, Brasil. Doutor em Economia pela Universidade Federal do Rio de Janeiro (UFRJ).<mdcarc@uol.com.br>

Correspondência: Rua Geraldo Martins, $\mathrm{n}^{\circ}$ 201, bloco 2, apto. 802, CEP 24220-380, Icaraí, Niterói, Rio de Janeiro, Brasil.

2 São clássicas, e fundamentais para o seu entendimento, as seguintes referências: Marini, 2005a e 2005b; Santos, 1970; Bambirra, 1978; e Caputo e Pizarro, 1970.

3 Sobre isso, ver Prado e Meireles, 2010 e Marini, 1992. 
4 A retomada do debate sobre a teoria marxista da dependência possui muitas referências. Destacamos aqui apenas algumas: Ferreira, Osorio e Luce, 2012; Amaral, 2006 e 2012; Duarte e Graciolli, 2007; Luce, 2011; Martins, 2011; Martins e Valencia, 2009; Osorio, 2004; e Valencia, 2003, 2005 e 2007.

5 "No caso da sociedade em forma especificamente capitalista, desenvolvimento significa, seguindo a mesma lógica, a operação das leis que emanam da organização própria da economia regida pelo capital em sentido extensivo (i.e., para uma porção mais ampla do globo, submetendo uma quantidade maior de formações sociais e seres humanos) e/ou intensivo (comandando momentos mais amplos da convivência social, como a atividade artística, esportiva, relações afetivas etc.). O trânsito desde um estágio mais baixo de desenvolvimento para um estágio mais alto significa, portanto, a predominância mais ampla da lógica capitalista na existência social (e não a passagem do pior ao melhor, como quer que esses estados sejam definidos)." (Bonente, 2012, p. 2-3)

6 Trata-se de um nível de abstração elevado porque, como demonstra Marx (1983, vol. 5, cap. 9-10), isso pressupõe que os preços de mercado correspondem aos preços de produção de mercado, que, por sua vez, correspondem aos valores de mercado. Ali, Marx observa que isso só é possível em setores de produção com composição orgânica do capital igual à média da economia (nesse caso específico de que estamos tratando, a economia mundial) e que apresentem, ademais, uma demanda por sua mercadoria equivalente ao volume de produção.

7 Nesse nível de abstração, considera-se apenas que a demanda é igual à oferta dessas mercadorias, de maneira que os preços efetivos de mercado correspondem aos preços de produção de mercado.

8 Maiores detalhes sobre esses mecanismos de transferência utilizando a lei do valor de Marx, no sentido que esse autor lhe deu - ou seja, enquanto uma lei de tendência -, podem ser vistos em Amaral e Carcanholo, 2009.

9 Note-se que Marx nunca procedeu assim. Procura-se assinalar apenas que a utilização do termo superexploração com base única e exclusivamente naquilo que Marx concebeu inclusive dentro dos níveis de abstração em que ele se encontrava em $O$ capital, permitiria, em alguns casos, esse tipo de interpretação.

10 E mesmo esse autor, em alguns momentos de sua obra, parece tratar indiferenciadamente essas duas coisas.

11 E isso por mais cruéis, lúgubres e desumanas que possam ser efetivamente as condições de trabalho no processo produtivo dentro da lógica capitalista.

12 “El gran aporte de Marini a la teoría de la dependencia fue haber demostrado cómo la superexplotación del trabajo configura una ley de movimiento propia del capitalismo dependiente. [A grande contribuição de Marini para a teoria da dependência foi ter demonstrado como a superexploração do trabalho constitui uma lei de movimento própria do capitalismo dependente.]" (Bambirra, 1978, p. 69-70)

13 A citação anterior de Marini pode dar a entender que se trata de troca desigual entre nações, como se ocorresse uma "exploração" de nações pobres por nações ricas. Como já apontado anteriormente, "nação", sem a devida qualificação da lógica capitalista que a caracteriza, constitui uma categoria vazia de sentido, ao menos para o marxismo. 
14 Seriam três formas: 1) intensificação do trabalho, sem compensação salarial; 2) elevação da jornada de trabalho, também sem compensação salarial; e 3) expropriação de parte do trabalho necessário para repor a força de trabalho. Haveria ainda uma quarta, não tratada por Marini nessa obra, que seria a elevação do valor da força de trabalho não acompanhada de um crescimento dos salários, ao menos não na mesma proporção.

15 Amaral (2012) faz uma boa tentativa para caracterizar a crise do capitalismo contemporâneo com base na dialética do capital fictício, e como essa atual conjuntura redefine a forma histórica tanto do imperialismo quanto da dependência contemporânea.

\section{Referências}

AMARAL, Marisa Silva. A investida neoliberal na América Latina e as novas determinações da dependência. 2006. Dissertação (Mestrado em Economia) - Programa de Pós-graduação em Economia, Universidade Federal de Uberlândia, Uberlândia, 2006.

. Teorias do imperialismo e da dependência: a atualização necessária ante a financeirização do capitalismo. 2012. Tese (Doutorado em Economia do Desenvolvimento) - Faculdade de Economia e Administração, Universidade de São Paulo, São Paulo, 2012.

; CARCANHOLO, Marcelo Dias. A superexploração do trabalho em economias periféricas dependentes. Katalysis, Florianópolis, v. 12, n. 2, 2009, p. 216-225.

BAMBIRRA, Vânia. Teoría de la dependencia: una anticrítica. México: Era, 1978.

BONENTE, Bianca Imbiriba. Desenvolvimento em Marx e na teoria econômica: por uma crítica negativa do desenvolvimento capitalista. 2012. Tese (Doutorado em Economia) - Programa de Pós-graduação em Economia, Universidade Federal Fluminense, Niterói, 2012.

CAPUTO, Orlando; PIZARRO, Roberto. Imperialismo, dependencia y relaciones económicas internacionales. Santiago: Centro de Estudios Socioeconómicos; Universidad de Chile, 1970. (Cuadernos de Estudios Socioeconómicos, 12-13).

DUARTE, Pedro Henrique; GRACIOLLI, Edílson A teoria da dependência: interpretações sobre o (sub)desenvolvimento na América Latina. In: COLÓQUIO INTERNACIONAL MARX/ENGELS, 5. Anais... Campinas: Unicamp, 2007.

FERREIRA, Carla; OSORIO, Jaime; LUCE, Mathias Seibel. Padrão de reprodução do capital: contribuições da teoria marxista da dependência. São Paulo: Boitempo, 2012.

LUCE, Mathias Seibel. A teoria do subimperialismo em Ruy Mauro Marini: contradições do capitalismo dependente e a questão do padrão de reprodução do capital. 2011. Tese (Doutorado em História) - Programa de Pós-graduação em História, Universidade Federal do Rio Grande do Sul, Porto Alegre, 2011.

MARINI, Ruy Mauro. América Latina: dependência e integração. São Paulo: Brasil Urgente, 1992.

. Dialética da dependência. In: TRASPADINI, Roberta; STEDILE, João Pedro (org.). Ruy Mauro Marini: vida e obra. São Paulo: Expressão Popular, 2005a, p. 137-180. 
Sobre a dialética da dependência. In: TRASPADINI, Roberta; STEDILE, João Pedro (Org.). Ruy Mauro Marini: vida e obra. São Paulo: Expressão Popular, 2005b, p. 181-194.

Subdesenvolvimento e revolução. Florianópolis: Insular, 2012.

MARTINS, Carlos Eduardo. Globalização, dependência e neoliberalismo na América Latina. São Paulo: Boitempo, 2011.

Valencia, Adrián Sotelo. A América Latina e os desafios da globalização: ensaios dedicados a Ruy Mauro Marini. Rio de Janeiro: PUC-Rio; São Paulo: Boitempo, 2009.

MARX, Karl. O capital: crítica da economia política. São Paulo: Abril Cultural, 1983. 5 volumes.

OSORIO, Jaime. Crítica de la economía vulgar: reproducción del capital y dependencia. México (D.F.): Miguel Ángel Porrua; Zacatecas (México): Universidad Autónoma de Zacatecas, 2004.
PRADO, Fernando; MEIRELES, Monika. Teoria marxista da dependência: elementos para a crítica ao novo-desenvolvimentismo dos atuais governos de centro-esquerda latino-americanos. In: CASTELO, Rodrigo. (org.). Encruzilhadas da América Latina no século XXI. Rio de Janeiro: Pão e Rosas, 2010, p. 169-190.

SANTOS, Theotonio dos. The Structure of Dependence. Nova York: The American Economic Review, 1970.

VALENCIA, Adrián Sotelo. América Latina: de crisis y paradigmas. La teoría de la dependencia en el siglo XXI. México (D.F.): Plaza y Valdés, 2005.

El mundo del trabajo en tensión: flexibilidad laboral y fracturación social en la década de 2000. México (D.F.): Plaza y Valdés, 2007.

La reestructuración del mundo del trabajo: superexplotación y nuevos paradigmas de la organización del trabajo. México (D.F.): Ítaca, 2003. 